\title{
Monitoring of Deformation Behaviour of Unsaturated Soil Slope using Distributed Optical Fibre Sensor
}

\author{
Dayangku Salma Awang Ismail $^{1 *}$, Azman Kassim² \\ ${ }^{1}$ Faculty of Engineering, \\ Universiti Malaysia Sarawak, 94300 Kota Samarahan, Sarawak, MALAYSIA \\ ${ }^{2}$ Faculty of Civil Engineering, \\ Universiti Teknologi Malaysia, 81310 Johor Bahru, Johor, MALAYSIA \\ *Corresponding Author
}

DOI: https://doi.org/10.30880/ijie.2020.12.09.024

Received 27 August 2020; Accepted 24 November 2020; Available online 30 December 2020

\begin{abstract}
A distributed optical fibre sensing system named Brillouin Optical Time Domain Analysis (BOTDA) is used to monitor the strain development of a laboratory soil slope model. The technology is yet to be fully implemented due to uncertainties of attachment method or the best way to set up optical fibre sensors for geostructure health monitoring. The aim of study is to evaluate the deformation behaviour subjected to the development of horizontal strains from Brillouin-based optical fibre sensor of a residual soil slope under loading impact using BOTDA technology. In this study, a soil-embedded strain sensor placement approach was proposed to be installed in the $1 \mathrm{~g}$ model of soil slope which was achieved via the horizontal planting of a three-layered optical fibre cable in S-curve forming slope. In this paper, however, only pilot tests result is demonstrated for preliminary data interpretation purposes. From the preliminary laboratory tests, the results show the soilembedded sensing fibre arrangement has efficiently detected and measured the horizontal strain deformation due to loading. Therefore, it can be concluded that the sensing fibre was well-responded with the soil movement under loading impact.
\end{abstract}

Keywords: Monitoring, deformation behaviour, distributed optical fibre sensor, unsaturated soil slope

\section{Introduction}

The risk of slope failure could be carefully monitored through periodic soil movement. The development of different kind of monitoring instruments in the past few decades improve the soil displacement monitoring results such as inclinometer, tiltmeter, extensometer etc. The results were used to characterize site condition, verification of design assumptions, determining the effect of construction, impose the quality of workmanship and provide indicators to failures. Alternatively, optical fibre technology was introduced in geo-structure instrumentation monitoring including natural slopes or embankments due to unsusceptible nature of optical fibre sensor to electromagnetic fields, corrosion, moisture, or ageing [1]. The directly surface contact to soil slope sensors arrangement is still under uncertain evaluation due to the non-linear soil behaviour that influences the true strain deformation of the soil slope. In this study, the laboratory-sized slope test model used the distributed optical fibre sensor (DOFS) technology and the monitoring sensors were arranged directly contact on the soil slope. The sensors measured the horizontal strain deformation of an unsaturated soil slope soil mass when subjected to rainwater infiltration and surcharge load-induced failure. However, the paper is only limited to present the measured strain of optical fibre sensors resulted from load-induced failure of unsaturated soil slope from the preliminary tests of this project. 